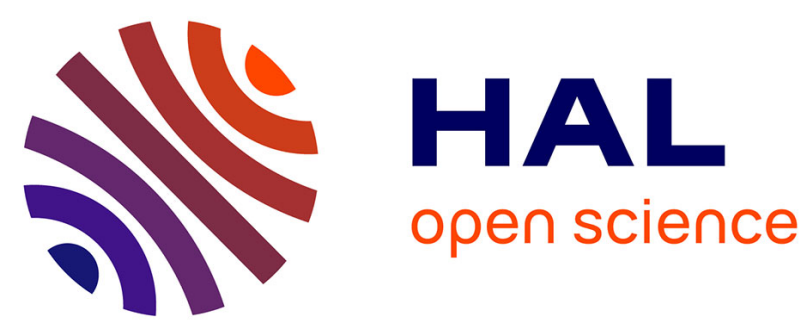

\title{
3,4,5-Trisubstituted-1,2,4-4-triazoles as WT and Y188L mutant HIV-1 non-nucleoside reverse transcriptase inhibitors: docking-based CoMFA and CoMSIA analyses
}

Elena Cichero, Laura Buffa, Paola Fossa

\section{- To cite this version:}

Elena Cichero, Laura Buffa, Paola Fossa. 3,4,5-Trisubstituted-1,2,4-4-triazoles as WT and Y188L mutant HIV-1 non-nucleoside reverse transcriptase inhibitors: docking-based CoMFA and CoMSIA analyses. Journal of Molecular Modeling, 2010, 17 (7), pp.1537-1550. 10.1007/s00894-010-0857-7 . hal-00629076

\section{HAL Id: hal-00629076 https://hal.science/hal-00629076}

Submitted on 5 Oct 2011

HAL is a multi-disciplinary open access archive for the deposit and dissemination of scientific research documents, whether they are published or not. The documents may come from teaching and research institutions in France or abroad, or from public or private research centers.
L'archive ouverte pluridisciplinaire HAL, est destinée au dépôt et à la diffusion de documents scientifiques de niveau recherche, publiés ou non, émanant des établissements d'enseignement et de recherche français ou étrangers, des laboratoires publics ou privés. 


\title{
3,4,5-Trisubstituted-1,2,4-4H-triazoles as WT and Y188L mutant HIV-1 non-nucleoside reverse transcriptase inhibitors: Docking- based CoMFA and CoMSIA analyses
}

Received: 30.07 .2010 / Accepted: 26.08.2010

Elena Cichero ${ }^{\bowtie}$, Laura Buffa, and Paola Fossa

Dipartimento di Scienze Farmaceutiche. Università degli Studi di Genova. Viale Benedetto XV n.3. 16132 - Genova. Italy

${ }^{\bowtie}$ Email: cichero@unige.it; Tel: +39-010-3538361; Fax: +39-010-3538358

\begin{abstract}
3,4,5-trisubstituted-1,2,4-4H-triazoles (TTs) have been recently identified as a new class of potent non-nucleoside HIV-1 Reverse Transcriptase (RT) inhibitors. Two series of triazoles have been studied, one of them was also screened against the Y188L mutant. A computational strategy based on molecular docking studies, followed by Comparative Molecular Fields Analysis (CoMFA) and Comparative Molecular Similarity Indices Analysis (CoMSIA), has been used to elucidate the atomic details of the RT/TT interactions and to identify the most important features impacting the TT antiretroviral activity. Two 3D-QSAR CoMFA and CoMSIA models were derived, using as dependent variable the $\mathrm{TT}_{\mathrm{pEC}} \mathrm{F}_{50}$ values measured against the wild-type (WT) HIV-1 (Model A) and the Y188L mutant form (Model B), respectively. The final model A CoMSIA $\left(\mathrm{r}_{\mathrm{ncv}}{ }^{2}=0.97, \mathrm{r}_{\mathrm{cv}}{ }^{2}=0.89, \mathrm{SEE}=0.314\right.$, and $\mathrm{r}_{\text {pred }}=$ $0.82)$ and model B CoMSIA $\left(\mathrm{r}_{\mathrm{ncv}}{ }^{2}=0.91, \mathrm{r}_{\mathrm{cv}}{ }^{2}=0.61, \mathrm{SEE}=0.236\right.$, and $\mathrm{r}^{2}$ pred $\left.=0.73\right)$ analyses were more predictive.

The results allowed us to obtain useful information for the design of new compounds with improved potency towards WT HIV-1 or potentially active against Y188L mutant.
\end{abstract}

Keywords HIV-1 $\cdot$ Reverse transcriptase $\cdot$ CoMFA $\cdot$ CoMSIA $\cdot$ Y188L HIV-1 mutant $\cdot$ Triazoles 


\section{Introduction}

Reverse transcriptase (RT) is a key enzyme in the HIV replication cycle and is one of the main targets in the development of drugs for treating HIV-infection and AIDS [1-5]. RT catalyzes the conversion of viral RNA into double stranded DNA that is then integrated in the host genome. Non-nucleoside RT inhibitors (NNRTIs) bind to an allosteric hydrophobic pocket (NNRTI binding site: NNIBS), located at about $10 \AA$ far from the polymerase active site and created upon inhibitor interaction, and lock the enzyme into an inactive form by affecting the geometry of the polymerase active site aspartyl residues [6]. In the past fifteen years, more than fifty structurally diverse NNRTIs have been described [6-12]. The fact that cross-resistance extends to the whole NNRTI class calls for development of new agents capable of inhibiting clinically relevant NNRTI-resistant mutants [13, 14].

Triazole derivatives, and in particular 3,4,5-trisubstituted-1,2,4-4H-triazoles (TTs), have been recently described as a novel class of potent NNRTIs [15, 16]. In 2006 Girardet and coworkers discussed a series of TTs bearing an amide function at the linker group, positioned between the sulfur atom (at the triazole position 3) and the R1 substituent (Fig. 1) [15].

Recently, Kirschberg and co-workers described a series of triazoles (active against WT HIV-1 RT) bearing a methylene as the linker located between the sulfur atom (at the triazole position 3) and the R1 substituent (Fig. 1) [16].

The first series of compounds displayed submicromolar or nanomolar potency against WT and (some of them) also against Y188L mutant while the second one was characterized by a loss of potency (micromolar log order) toward the WT.

With the aim to elucidate the most important RT/TT interactions and to identify the features really impacting the TT antiretroviral activity, we performed a computational study on a dataset of 97 TTs, selected from the two series of triazoles described above. Our aim was also to elaborate a quantitative structure-activity relationship (QSAR) model for enabling the TT antiretroviral activity prediction prior to synthesis, and to obtain useful suggestions for the design of new TTs with improved potency also against Y188L mutant. 
On the basis of the crystal structure of RT in complex with 4-benzyl-3-[(2chlorobenzyl)sulfanyl]-5-thien- 2-yl-4H-1,2,4-triazole (TT 18) [16], a flexible docking simulation was performed on compounds 1-97. The most probable docking poses were selected and submitted to 3D-QSAR studies involving Comparative Molecular Fields Analysis (CoMFA) and Comparative Molecular Similarity Indices Analysis (CoMSIA). Two 3D-QSAR CoMFA and CoMSIA models were derived, using as dependent variable the TT $\mathrm{pEC}_{50}$ values measured against the wild-type (WT) HIV-1 (Model A) and the Y188L mutant form (Model B), respectively. These results allowed us to obtain useful information for the design of new compounds with improved potency towards WT HIV-1 or potentially active against Y188L mutant.

\section{Materials and methods}

\section{Data set}

A dataset of 97 triazoles was selected from two sample data sets. TTs 1-31 (Table 1) [16] and TTs 32-97 (Table 2) [15] were screened against WT HIV-1 on MT-2 cells and HeLa-JC53 cells, respectively. Furthermore, some compounds belonging to series 2 (39-47, 53-68 and 7596) were also screend against Y188L mutant.

Since 1-97 $\mathrm{pEC}_{50}$ values are comparable (Efavirenz has been used as biological assays reference compound on both the two cell lines, displaying results within the same order of magnitude), all the compounds were submitted to CoMFA and CoMSIA analyses (using as the dependent variable the TT $\mathrm{pEC}_{50}$ values measured against the WT HIV-1, Model A).

In addition, CoMFA and CoMSIA models were also derived, using as the dependent variable the 39-47, 53-68 and 75-96 $\mathrm{pEC}_{50}$ values, measured against the Y188L mutant form (Model B).

The molecular structures of compounds 1-97 (Tables 1, 2) were built, parameterized (Gasteiger-Hückel method) and energy minimized within MOE using MMFF94 force field [17]. 


\section{Docking-based ligand alignment}

To locate the appropriate binding orientations and conformations of triazole derivatives within the NNIBS, a computational searching method was applied. Starting from a database including all the 97 compounds, a docking procedure was performed. Thus, on the basis of the three-dimensional structure coordinates of the RT/18 complex (PDB entry 2RKI) [16] (18 in the bioactive conformation), each inhibitor was docked into the NNIBS using the flexible docking module implemented in Surflex [18]. Surflex-Dock uses an empirically derived scoring function that is based on the binding affinities of protein-ligand complexes and on their X-ray structures.

Since for all compounds the best-docked geometries were in agreement with the crystallographic data of the RT/18 complex (and thus already aligned), they were directly submitted to CoMFA [19] and CoMSIA [20] studies by Sybyl1.0 software [21].

\section{D- QSAR analysis}

\section{Training set and test set}

For both the models (A and B), the training and the test set compounds were divided manually according to a representative range of biological activities and structural variations. For QSAR analysis, $\mathrm{EC}_{50}$ values have been transformed into $\mathrm{pEC}_{50}$ values and then used as response variables. Compound binding affinity covered $4 \log$ orders of magnitude.

Triazole derivatives 1-97 (TTs as WT NNRTIs, Model A)

All the compounds were grouped into a training set $(1,3,4,6,7,10,11,13,14,16,19,22$, 24-31, 33, 36, 39, 41, 45, 48-51, 53, 54, 57-60, 64-71, 77, 78, 80, 81, 84, 86-88, 90, 91, 9496) for model generation and into a test set $(2,5,8,9,12,15,17,18,20,21,23,32,34,35$, $37,38,40,42-44,46,47,52,55,56,61-63,72-76,79,82,83,85,89,92,93,97)$ for model validation, containing 56 and 41 compounds respectively. 
Triazole derivatives 39-47, 53-68 and 75-96 (TTs as Y188L mutant NNRTIs, Model B)

Compounds 39-47, 53-68 and 75-96 were divided into a training set (39-44, 47, 53-59, 61-64, $67,68,75-80,82-92,95)$ for model generation and into a test set $(45,46,60,65,66,81,93$, 94, 96) for model validation, containing 38 and 9 compounds respectively.

\section{CoMFA and CoMSIA analyses}

CoMFA method is a widely used 3D-QSAR technique to relate the biological activity of a series of molecules with their steric and electrostatic fields, which are calculated placing the aligned molecules, one by one, in a 3D cubic lattice with a $2 \AA$ grid spacing. The van der Waals potential and Coulombic terms, which represent steric and electrostatic fields, respectively, were calculated using the standard Tripos force field method. The columnfiltering threshold value was set to $2.0 \mathrm{kcal} \mathrm{mol}^{-1}$ to improve the signal-noise ratio. A methyl probe with +1 charge was used to calculate the CoMFA steric and electrostatic fields. A 30 $\mathrm{kcal} \mathrm{mol}^{-1}$ energy cut-off was applied to avoid infinity of energy values inside the molecule.

CoMSIA method calculates five descriptors, namely the steric, electrostatic, and hydrophobic parameters and the $\mathrm{H}$-bond donor and $\mathrm{H}$-bond acceptor properties. The similarity index descriptors were calculated using the same lattice box employed for the CoMFA calculations and an $\mathrm{sp}^{3}$ carbon as a probe atom with +1 charge, +1 hydrophobicity and $+1 \mathrm{H}$-bond donor and +1 H-bond acceptor properties.

\section{Partial least square analysis and models validation}

Partial least-squares (PLS) method approach, an extension of the multiple regression analysis, was used to derive the 3D-QSAR models in which the CoMFA and CoMSIA descriptors were used as independent variables and $\mathrm{pEC}_{50}$ values were used as dependent variables. Leave one out (LOO) cross-validation method was used to check the predictivity of the derived model and to identify the optimal number of components (ONC) leading to the highest crossvalidated $\mathrm{r}^{2}\left(r_{c v}^{2}\right)$. In the LOO methodology, one molecule is omitted from the dataset and a model is derived involving the rest of the compounds. Then, employing this model, the activity of the omitted molecule is predicted. 
The ONC obtained from cross-validation methodology was used in the subsequent regression model. Final CoMFA and CoMSIA models were generated using non-cross-validated PLS analysis. To further assess the statistical confidence and robustness of the derived models, a 100-cycle bootstrap analysis was performed. This is a procedure in which $n$ random selections out of the original set of $n$ objects are performed several times (100-times were required to obtain a good statistical information). In each run, some objects may not be included in the PLS analysis, whereas some others might be included more then once. The mean correlation coefficient is represented as bootstrap $r^{2}\left(\mathrm{r}^{2}\right.$ boot $)$. To validate the CoMFA and CoMSIA derived models, the predictive ability for the test set of compounds (expressed as $r_{\text {pred }}^{2}$ ) was determined by using the following equation:

$$
\mathrm{r}_{\text {pred }}^{2}=(\mathrm{SD}-\mathrm{PRESS}) / \mathrm{SD}
$$

$\mathrm{SD}$ is the sum of the squared deviations between the biological activities of the test set molecules and the mean activity of the training set compounds and PRESS is the sum of the squared deviation between the observed and the predicted activities of the test set compounds.

All the calculations were carried out using a PC with the Windows XP operating system.

\section{Results and discussion}

\section{Docking-based ligand alignment}

In this work, for the molecular modeling analysis we used the X-ray coordinates of the crystal structure of TT 18/RT complex. According to our calculations, all inhibitors display at least an H-bond between the K103 $\varepsilon$-amino group and the $\mathrm{N} 1$ or $\mathrm{N} 2$ atoms of the triazole ring, while several van der Waals and $\pi-\pi$ interactions with two hydrophobic pockets $\left(\mathrm{P}_{1}\right.$ and $\left.\mathrm{P}_{2}\right)$ are detected. As shown in Fig. 2, region $\mathrm{P}_{1}$ (occupied by the TTs-R2 substituent) includes P95, Y181, Y188 and W229 residues, while $\mathrm{P}_{2}$ (occupied by the TTs-R1 substituent) consists of K104, V106, F227, L234, H235, P236 and Y318 residues. All the compounds orient the R3 group towards the NNIBS residues E138, V179, I180.

In addition, compounds 75-96 (the most active of the series, $\mathrm{pEC}_{50}=8.40-10.00$ ) display $\mathrm{H}$ bond interactions between the R1 sulfonamide moiety and NNIBS residues K104 (the 
backbone carbonyl oxygen atom) and V106 (the backbone nitrogen portion), while the amide linker (located between the R1 group and the sulfur atom at the triazole position 3 ) is involved in a double H-bond with H235 and Y318. On the contrary, compounds 1-31 do not display additional $\mathrm{H}$-bond interactions within the $\mathrm{P} 2$ pocket, showing a loss of potency $\left(\mathrm{pEC}_{50}=4.29\right.$ 6.88) toward the WT.

In order to validate the docking procedure, we compared the most probable binding pose, selected for each compound, with the X-ray structure of $\mathbf{1 8}$ in complex with RT, obtaining ligand conformations perfectly superposed on the available crystallographic data. Thus, they were aligned together inside the NNIBS for the following 3D-QSAR analysis.

\section{CoMFA and CoMSIA analyses}

\section{Model A}

CoMFA and CoMSIA studies were developed using, respectively, CoMFA steric and electrostatic fields and CoMSIA steric, electrostatic, hydrophobic, H-bond donor and H-bond acceptor properties, as independent variables, and the ligand $\mathrm{pEC}_{50}$ as a dependent variable.

The final CoMFA model was generated employing non-cross-validated PLS analysis with the optimum number of components $(\mathrm{ONC}=5)$ to give a non-cross validated $\mathrm{r}^{2}\left(\mathrm{r}^{2}{ }_{\text {ncv }}\right)=0.984$, test set $r^{2}\left(r_{\text {pred }}^{2}\right)=0.80$, Standard Error of Estimate $(\mathrm{SEE})=0.229$, steric contribution $=0.700$ and electrostatic contribution $=0.300$. The reliability of the model thus generated was supported by bootstrapping results.

A CoMSIA model consisting of steric, electrostatic, hydrophobic, H-bond donor and H-bond acceptor fields with $\mathrm{a}^{2}{ }_{\text {ncv }}=0.970, \mathrm{r}_{\text {pred }}^{2}=0.82, \mathrm{SEE}=0.314$, steric contribution $=0.178$, electrostatic contribution $=0.144$, hydrophobic contribution $=0.257$, H-bond acceptor contribution $=0.230$ and $\mathrm{H}$-bond donor contribution $=0.191$ was derived. All statistical parameters supporting CoMFA and CoMSIA models are reported in Online Resource 1.

Experimental and predicted binding affinities values for the training set and test set are reported in Online Resource 2. 
As shown in Fig. 3a (for simplicity, only the structure of compound $\mathbf{1 5}$ and 83, displaying high $\mathrm{WT} \mathrm{pEC}_{50}$ values, are depicted as representative of the two series), the steric contour map predicts for compounds 1-31 (series 1) favorable interaction polyhedra (green areas) near one of the two ortho positions of the R1 phenyl ring while unfavorable areas (reported in yellow) are depicted around the two R1 meta positions. Yellow polyhedra also surround the

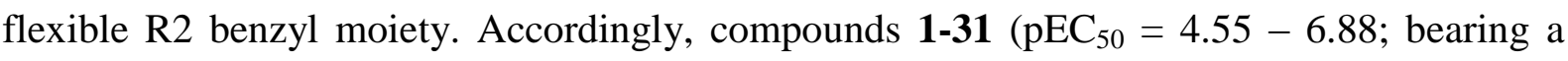
benzyl moiety at the $\mathrm{R} 2$ substituent) show lower $\mathrm{pEC}_{50}$ values in comparison with those of compounds 32-97 $\left(\mathrm{pEC}_{50}=5.64-10.00\right.$ s bearing no flexible R2 substituents).

As far as compounds 32-97 (series 2) are concerned, favorable interaction polyhedra (green) are located in proximity of the 1-naphthyl position 4 and 8 at the R2 substituent (or around the position 2 and 4 for those compounds bearing a phenyl ring instead of a 1-naphthyl one), and around the para and one of the two ortho positions of the R1 phenyl moiety. The reliability of the steric map calculations is verified by the higher $\mathrm{pEC}_{50}$ values of those compounds bearing a 4-substituted-1-naphthyl moiety (or a 4-substituted phenyl ring) at the R2 substituent in comparison with those of TTs bearing the 1-naphthyl or phenyl moiety (unsubstituted) in R2. These results are also supported by the high $\mathrm{pEC}_{50}$ values of those triazoles bearing a sulfonyl moiety at the R1 phenyl ring para-position (instead of a methyl one)..

On the contrary, unfavorable polyhedra (yellow) are depicted around the linker amide group oxygen atom and in proximity of the 1- naphthyl position 6 and 7 at the R2 substituent (underlining the beneficial introduction of the phenyl moiety, instead of the 1-naphthyl one).

The electrostatic field contour map of the CoMFA analysis plotted in Fig. 3b (for simplicity, only the structure of compound $\mathbf{1 5}$ and $\mathbf{8 3}$, displaying high $\mathrm{WT}_{\mathrm{pEC}} \mathrm{F}_{50}$ values, are depicted as representative of the two series), predicts for compounds 1-31 (series 1) favorable electropositive substituents (blu polyhedra) around the R1 (hetero)aryl moiety para position and in proximity of compound 15 3-thienyl ring sulfur atom (R3 substituent). These results are in agreement with the slightly higher $\mathrm{pEC}_{50}$ values of $\mathbf{1 4}\left(\mathrm{R} 1=4\right.$-methoxy-phenyl; $\mathrm{pEC}_{50}$ $=5.52)$ in comparison with that of $12\left(\mathrm{R} 1=4\right.$-cyanophenyl; $\left.\mathrm{pEC}_{50}=4.63\right)$ and are also verified by the difference in $\mathrm{pEC}_{50}$ among those compounds bearing a 2-thienyl moiety at the triazole R3 substituent (instead of a 3-thienyl one).

Regarding TTs 32-97 (series 2), less positive moieties are predicted to be favored (red areas) in proximity of the $\mathrm{R} 1$ phenyl ring para-position ( $\mathbf{8 3}$ sulfonyl oxygen atoms), near the triazole 
$\mathrm{N} 1$ and N2 nitrogen atoms and around the linker amide group. Accordingly, compounds 32$97\left(\mathrm{pEC}_{50}=5.64-10.00\right.$; bearing an amide function as a linker between the sulfur atom at the triazole position 3 and the $\mathrm{R} 1$ phenyl moiety) show higher $\mathrm{pEC}_{50}$ values in comparison with compounds 1-31 $\left[\mathrm{pEC}_{50}=4.55-6.88\right.$; bearing a methylene linker between the sulfur atom at the triazole position 3 and the R1 (hetero)aryl moiety].

In addition, more electropositive substituents are predicted to be beneficial (blue area) around the linker methylene, on the R1 phenyl ring plane, and in proximity of the 1-naphthyl ring position 2 (R2 substituent). The presence of electropositive groups is also allowed near the 1naphthyl position 8 . These results are supported by the high $\mathrm{pEC}_{50}$ values of those triazoles bearing a sulfonyl moiety at the R1 phenyl ring para-position (instead of a methyl one)], or a 1-naphthyl group (instead of a 8-quinoline moiety) at the triazole R2 substituent

The CoMSIA steric and electrostatic regions are in agreement with the CoMFA steric and electrostatic areas.

The calculated CoMSIA hydrophobic contours (Fig. 4, for simplicity, only the structure of compound 15 and $\mathbf{8 3}$, displaying high $\mathrm{WT}_{\mathrm{pEC}}$. values, are depicted as representative of the two series) display favorable hydrophobic substituents (yellow polyhedra) in proximity of the methylene of the R2 benzyl group (compounds 1-31, series 1) and of the carbon atom of the R2 1-naphthyl group (compounds 32-97, series 2). Yellow polyhedra also surround the meta positions of the R1 (hetero)aryl moiety (compounds 1-31). On the contrary, hydrophobic moieties are predicted to be disfavored (white areas) in proximity of compound 15 3-thienyl ring sulfur atom (R3 substituent, compounds 1-31) and near compounds 32-97 (i) R1 phenyl ring para position, (ii) R3 substituent and (iii) around the linker amide group.

CoMSIA H-bond acceptor map (see Online Resource 3) illustrates that H-bond acceptor groups are predicted to be beneficial (magenta areas) near the triazole N1 and N2 nitrogen atoms (for both the two series) and in proximity of compounds 32-97 R1 phenyl ring para position and of the linker amide group oxygen atoms. The presence of $\mathrm{H}$-bond acceptor seems to be disfavored near the meta positions of the R1 (hetero)aryl moiety (compounds 1-31) and around the R1 sulfonylamide moiety nitrogen atom (compounds 75-96). the higher $\mathrm{pEC}_{50}$ values of those triazoles bearing a sulfonyl moiety at the R1 phenyl ring para-position (instead of a methyl one) and with the difference in $\mathrm{pEC}_{50}$ values between compounds 32-97 $\left(\mathrm{pEC}_{50}=5.64-10.00\right.$, bearing an amide group as a linker between the sulfur atom at the 
triazole position 3 and the R1 phenyl moiety) and 1-31 $\left[\mathrm{pEC}_{50}=4.55-6.88\right.$; bearing a methylene linker between the sulfur atom at the triazole position 3 and the R1 (hetero)aryl moiety].

Accordingly, H-bond donor functions (see Online Resource 3) would result to be beneficial (cyan areas) and detrimental (purple polyhedra) around 75-96 R1 sulfonylamide moiety nitrogen and oxygen atoms, respectively. Purple polyhedra are also located in the proximity of the triazole N1 and N2 nitrogen atoms (for both the two series) and near the linker amide function (for compounds 32-97).

In order to verify the reliability of the 3D-QSAR analyses, Model A CoMFA and CoMSIA maps have been compared with the results of the docking analysis. Briefly, the CoMFA steric model proves to match with the NNIBS 3D topology, suggesting bulky substitution in proximity of the $\mathrm{P}_{1}$ pocket occupied by the $\mathrm{R} 2$ substituent (involved in $\pi-\pi$ stacking interactions with Y181, Y188 and W229). The CoMFA electrostatic map points out the beneficial presence of small electropositive substituents at the R3 substituent, establishing hydrophobic contacts with V179 and I180.

The CoMSIA H-bond acceptor and H-bond donor maps confirm the importance of the formation of hydrogen bond interactions to stabilize the RT/TT complex. Accordingly, compounds 75-96 (the most active TTs of the two series, $\mathrm{pEC}_{50}$ range $=8.40-10.00$ ) bear the following three $\mathrm{H}$-bond acceptor centers: $(i)$ at the para position of the $\mathrm{R} 1$ phenyl ring $(\mathrm{H}-$ bond with H235 and Y318), (ii) at the linker portion (H-bond with K104 and V106), (iii) and at the triazole ring (K103). On the contrary, compounds 1-31 show lower $\mathrm{pEC}_{50}$ values ( $\mathrm{pEC}_{50}$ range $=4.29-6.88$ ) because of the absence of $\mathrm{H}$-bond acceptor functions at the TT R1 and linker groups.

\section{Model B}

CoMFA and CoMSIA studies were developed using, respectively, CoMFA steric and electrostatic fields and CoMSIA steric, electrostatic, hydrophobic, H-bond donor and H-bond acceptor properties, as independent variables, and the ligand $\mathrm{pEC}_{50}$ as a dependent variable.

The final CoMFA model was generated employing non-cross-validated PLS analysis with the optimum number of components $(\mathrm{ONC}=6)$ to give a non-cross validated $\mathrm{r}^{2}\left(\mathrm{r}^{2}{ }_{\mathrm{ncv}}\right)=0.967$, 
test set $r^{2}\left(r^{2}\right.$ pred $)=0.64$, Standard Error of Estimate $(\mathrm{SEE})=0.149$, steric contribution $=0.684$ and electrostatic contribution $=0.316$. The reliability of the model thus generated was supported by bootstrapping results.

A CoMSIA model consisting of steric, electrostatic, hydrophobic, H-bond donor and H-bond acceptor fields with $\mathrm{a}^{2}{ }_{\text {ncv }}=0.913, \mathrm{r}_{\text {pred }}^{2}=0.73, \mathrm{SEE}=0.236$, steric contribution $=0.172$, electrostatic contribution $=0.153$, hydrophobic contribution $=0.231$, H-bond acceptor contribution $=0.164$ and $\mathrm{H}$-bond donor contribution $=0.281$ was derived. All statistical parameters supporting CoMFA and CoMSIA models are reported in Online Resource 4.

Experimental and predicted binding affinities values for the training set and test set are reported in Online Resource 5. Distribution of experimental and predicted $\mathrm{pEC}_{50}$ values for training set and for test set compounds according to model B CoMFAand CoMSIA analyses is reported in Fig. 5

As shown in Fig. 6a (for simplicity, only the structure of compound 92 is depicted as representative), the steric contour map predicts favorable interaction polyhedra (green) around the the R2 substituent 8-quinoline (or 1-naphthyl) moiety positions 2 and 5 (or positions 4 and 7). The introduction of a small group at the positions 4 and 6 of the 8-quinoline moiety is also allowed (or around the positions 3 and 5 for those TTs bearing a 1-naphthyl ring in R2). The reliability of the steric map calculations is verified by the higher $\mathrm{pEC}_{50}$ values of those compounds bearing a 4-substituted-1-naphthyl moiety (or a 4-substituted phenyl ring) at the R2 substituent in comparison with those of TTs bearing the 1-naphthyl or phenyl moiety (unsubstituted) in R2.

Unfavorable polyhedra (yellow) surround the oxygen atom of the linker carbonyl group, one of the ortho position and both the meta positions of the para substituted phenyl ring (R1 substituent). Yellow areas are also located around the trifluoromethyl substituent (R3 substituent) and around the 8-quinoline (or 1-naphthyl) moiety positions 1 and 3 (or positions 6 and 8).

On the basis of the electrostatic fields contour map of the CoMFA analysis plotted in Fig. 6b (for simplicity, only the structure of compound $\mathbf{9 2}$ is depicted as representative), less positive moieties would be favored (red polyhedra) in proximity of the amide and sulfonyl oxygen atoms (see 32-97 linker and R1 substituent), near the 8-quinolinyl (or 1-naphthyl) position 6 
(or position 3) at the R2 substituent and around the trifluoromethyl group (R3 substituent). On the other hand, more electropositive substituents are predicted to be beneficial (blue area) around the 8-quinolinyl (or 1-naphthyl) position 1 (or position 8) at the R2 substituent.

These results are supported by the high $\mathrm{pEC}_{50}$ values of those triazoles bearing a sulfonyl moiety at the R1 phenyl ring para-position (instead of a methyl one), a trifluoromethyl group at the R3 substituent (instead of a methyl one) or a 1-naphthyl ring (instead of a 8-quinoline moiety) at the R2 substituent.

The CoMSIA steric and electrostatic regions are in agreement with the CoMFA steric and electrostatic areas.

As shown in Fig. 7 (for simplicity, only the structure of compound 92 is depicted as representative), the introduction of small hydrophobic substituents (yellow polyhedra) in proximity of the 8-quinolinyl (or 1-naphthyl) moiety positions 1 and 5 (or position 4 and 8) at the R2 substituent, around the trifluoromethyl substituent (R3 substituent) and around one of the R1 phenyl ring ortho-position is allowed. The reliability of the hydrophobic map calculation is verified by the higher $\mathrm{pEC}_{50}$ values of those TTs bearing a 4-alkyl-1-naphthyl moiety at the R2 substituent in comparison with those of TTs bearing a 4-methoxy-1-naphthyl moiety in $\mathrm{R} 2$. These results are also supported by the high $\mathrm{pEC}_{50}$ values of those TTs bearing a 1-naphthyl group (instead of a 8-quinoline moiety) at the R2 substituent or a trifluoromethyl group (instead of a methyl one) at the R3 substituent.

The model B CoMSIA H-bond acceptor map (see Online Resource 5) shows that the introduction of groups bearing $\mathrm{H}$-bond acceptor functions on the $\mathrm{R} 1$ phenyl ring para-position would be beneficial (magenta polyhedra). On the contrary, H-bond acceptor functions are predicted to be disfavored (green areas) in proximity of the 8-quinolinyl position 1 (or 1naphthyl position 8) at the R2 substituent. Accordingly, H-bond donors are predicted to be favorable (cyan region) and unfavorable (purple region) near the R1 sulfonylamide nitrogen atom and oxygen atoms, respectively (see Online Resource 5). In addition, purple polyhedra are also located around the R2 8-quinolinyl (or 1-naphthyl) position 7 (or position 2). These results are supported by the evidence of the high affinity levels of compounds bearing a sulfonyl moiety at the R1 phenyl ring para-position (instead of a methyl one). 
Comparing these results with those obtained from model A, we have identified the following key features enhancing the TT activity towards the Y188L mutant (instead of against the WT): (i) the introduction of a small substituent at the 1-naphthyl position 3 is allowed (compare CoMFA steric contour map around R2, reported in Fig.7a and in Fig. 3a), (ii) electronegative groups around the 1-naphthyl position 3 (compare CoMFA electrostatic contour map around R2, reported in Fig.7b and in Fig. 3b) and (iii) hydrophobic group in proximity of R3 (compare CoMSIA hydrophobic contour map reported in Fig.4 and in Fig. 7).

On the basis of these results, the introduction of a 3-quinolinyl moiety at substituent R2, and of an alkyl- (isopropyl-, cyclopropyl- or $t$-butyl) group at substituent R3 seem particularly favorable to increase the TT potency against the Y188L mutant. In addition, a 3,5-dimethylphenyl or a 2-naphthyl moiety could result to be effective as an R2 substituent.

\section{Conclusions}

The computational studies presented here analyze the main interactions responsible for TTs activity and give useful suggestions for the synthesis of new analogues with improved potency against the WT HIV-1 and also against the Y188L mutant.

The models elaborated will be exploited to design new TTs and predict their activity prior to synthesis.

\section{Acknowledgments}

This work was financially supported by the University of Genova. Dr. B. Domenichini is gratefully acknowledged. E.C. was financially supported by a post-doc fellowship, Area Chimica, University of Genova. 


\section{References}

1. Jonckheere H, Anne J, De Clercq E (2000) The HIV-1 reverse transcription (RT) process as target for RT inhibitors. Med Res Rev 20:129-154

2. De Clercq E (2001) New developments in anti-HIV chemotherapy. Farmaco 56:3-12

3. De Clercq E (2005) Emerging anti-HIV drugs. Expert Opin Emerg Drugs 10:241-273

4. De Clercq E (2005) New approaches toward anti-HIV chemotherapy. E J Med Chem 48:1297-1313

5. Barbaro G, Scozzafava A, Mastrolorenzo A, Supuran CT (2005) Highly active antiretroviral therapy:current state of the art, new agents and their pharmacological interactions useful for improving therapeutic outcome. Curr Pharm Des 11:1805-1843

6. Balzarini J (2004) Current status of the non-nucleoside reverse transcriptase inhibitors of human immunodeficiency virus type 1. Curr Top Med Chem 4:921-944

7. De Clercq E (1998) The role of non-nucleoside reverse transcriptase inhibitors (NNRTIs) in the therapy of HIV-1 infection. Antiviral Res 38:153-179

8. Pedersen OS, Pedersen EB (1999) Non-nucleoside reverse transcriptase inhibitors, the NNRTI boom. Antivir Chem Chemother 10:285-314

9. Pedersen OS, Pedersen EB (2000) The flourishing syntheses of non-nucleoside reverse transcriptase inhibitors. Synthesis 2000 4:479-495

10. Campiani G, Ramunno A, Maga G, Nacci V, Fattorusso C, Catalanotti B, Morelli E, Novellino E (2002) Non-nucleoside HIV-1 reverse transcriptase (RT) inhibitors:past, present, and future perspectives. Curr Pharm Des 8:615-657

11. De Clercq E (2004) Non-nucleoside reverse transcriptase inhibitors (NNRTIs):past, present, and future Chem Biodiversity 1:44-64

12. Pauwels R (2004) New non-nucleoside reverse transcriptase inhibitors (NNRTIs) in development for the treatment of HIV infections. Curr Opin Pharmacol 4:437-446

13. Leigh Brown AJ, Frost SD, Mathews WC, Dawson K, Hellmann NS, Daar ES, Richman DD, Little SJ (2003) Transmission fitness of drug-resistant human immunodeficiency virus and the prevalence of resistance in the antiretroviral-treated population. J Infect Dis 187:683-686

14. Richman DD, Morton SC, Wrin T, Hellmann N, Berry S, Shapiro MF, Bozzette SA (2004) The prevalence of antiretroviral drug resistance in the United States. AIDS 18:1393-1401 
15. De La Rosa M, Kim HW, Gunic E, Jenket C, Boyle U, Koh YH, Korboukh I, Allan M, Zhang W, Chen H, Xu W, Nilar S, Yao N, Hamatake R, Lang SA, Hong Z, Zhang Z, Girardet JL (2006) Tri-substituted triazoles as potent non-nucleoside inhibitors of the HIV-1 reverse transcriptase. Bioorg Med Chem Lett 16:4444-4449

16. Kirschberg TA, Balakrishnan M, Huang W, Hluhanich R, Kutty N, Liclican AC, McColl DJ, Squires NH, Lansdon EB (2007) Triazole derivatives as non-nucleoside inhibitors of HIV-1 reverse transcriptase--structure-activity relationships and crystallographic analysis. Bioorg Med Chem Lett 18:1131-1134

17. MOE:Chemical Computing Group Inc. Montreal. H3A 2R7 Canada. http://www.chemcomp.com

18. Jain AN (1996) Scoring noncovalent protein-ligand interactions:A continuous differentiable function tuned to compute binding affinities. J Comput Aided-Mol Des $10: 427-440$

19. Cramer III RD, Patterson DE, Bunce JD (1989) Recent advances in comparative molecular field analysis (CoMFA). Prog Clin Biol Res 291:161-165

20. Klebe G, Abraham U, Mietzner T (1994) Molecular similarity indices in a comparative analysis (CoMSIA) of drug molecules to correlate and predict their biological activity. $\mathrm{J}$ Med Chem 37:4130-4146

21. Sybyl 1 0. Tripos Inc 1699 South Hanley Road. St Louis. Missouri. 63144. USA 


\section{Tables}

Table 1 Molecular structure of triazoles derivatives 1-31

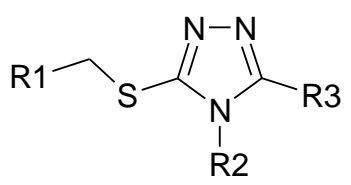

(1)


Table 1 continued

\begin{tabular}{|c|c|c|c|c|}
\hline Comp. & $\mathrm{R} 1$ & $\mathrm{R} 2$ & R3 & $\mathrm{WT}_{\mathrm{pEC}} \mathrm{p}_{50}$ \\
\hline 17 & & & & 4.29 \\
\hline 18 & & & & 6.36 \\
\hline 19 & & & & 5.77 \\
\hline 20 & & & & 5.70 \\
\hline 21 & & & & 6.24 \\
\hline 22 & & & & 5.77 \\
\hline 23 & & & & 5.33 \\
\hline 24 & & & & 5.05 \\
\hline 25 & & & & 5.48 \\
\hline 26 & & & & 5.89 \\
\hline 27 & & & & 5.62 \\
\hline 28 & & & & 5.46 \\
\hline 29 & & & & 6.00 \\
\hline 30 & & & & 5.96 \\
\hline 31 & & & & 6.14 \\
\hline
\end{tabular}


Table 2 Molecular structure of triazole derivatives 32-97

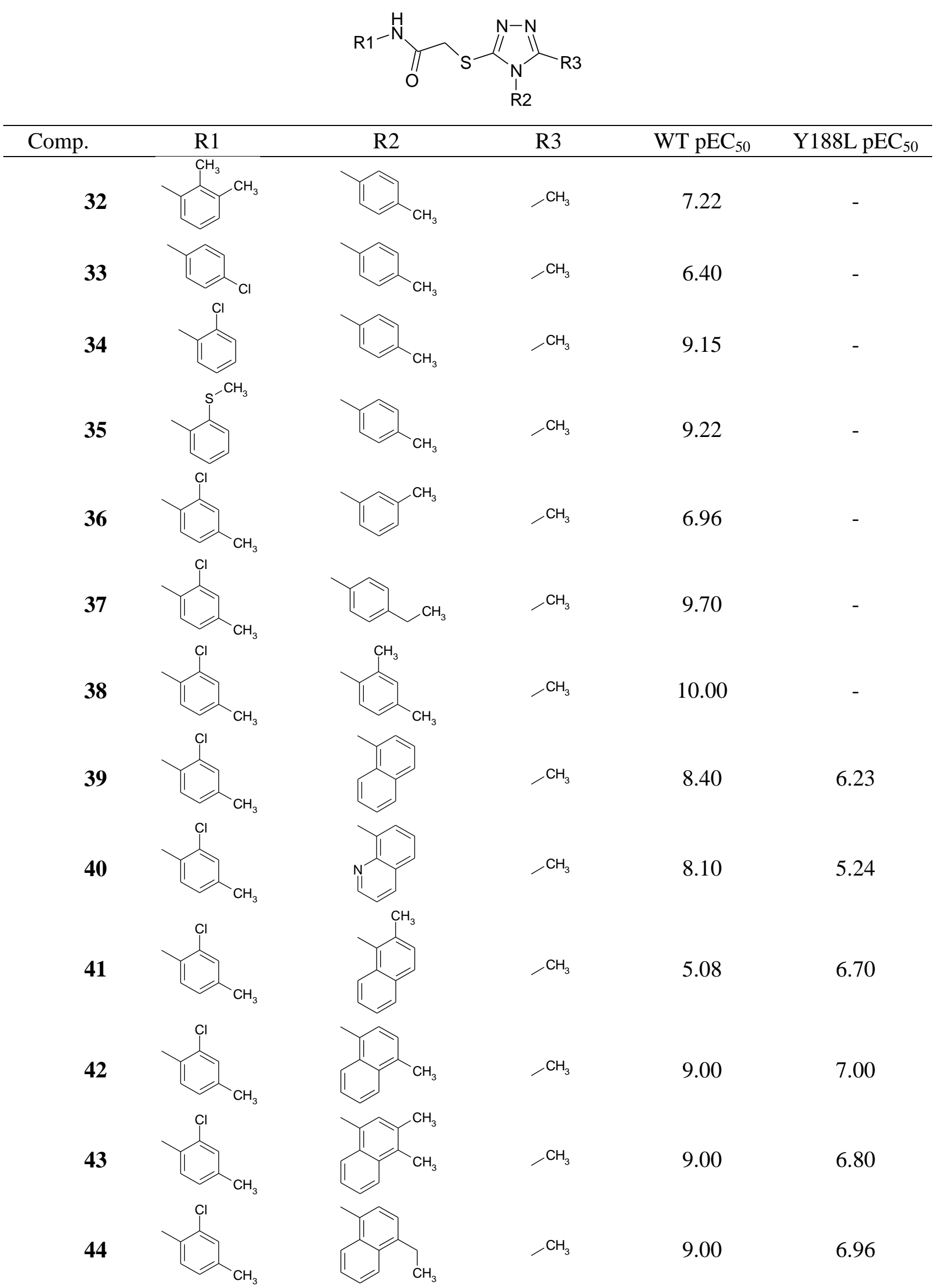


Table 2 continued<smiles>[R7]NC(=O)CSc1nnc([R3])n1[R2]</smiles>

\begin{tabular}{|c|c|c|c|c|c|}
\hline Comp. & $\mathrm{R} 1$ & $\mathrm{R} 2$ & R3 & $\mathrm{WT}_{\mathrm{pEC}} \mathrm{C}_{50}$ & $\mathrm{Y}_{188 \mathrm{~L} \mathrm{pEC}} \mathrm{p}_{50}$ \\
\hline 45 & & & $-\mathrm{CH}_{3}$ & 9.00 & 7.05 \\
\hline 46 & & & & 9.00 & 6.62 \\
\hline 47 & & & & 9.00 & 6.49 \\
\hline 48 & & & $-\mathrm{CH}_{3}$ & 8.52 & - \\
\hline 49 & & & & 8.15 & - \\
\hline 50 & & & & 7.00 & - \\
\hline 51 & & & & 8.30 & - \\
\hline 52 & & & $-\mathrm{CH}_{3}$ & 9.40 & - \\
\hline 53 & & & $-\mathrm{CH}_{3}$ & 8.70 & 6.14 \\
\hline 54 & & & $-\mathrm{CH}_{3}$ & 8.15 & 5.38 \\
\hline 55 & & & $-\mathrm{CH}_{3}$ & 9.00 & 6.68 \\
\hline
\end{tabular}


Table 2 continued<smiles>[R7]NC(=O)CSc1nnc([R3])n1[R2]</smiles>

\begin{tabular}{|c|c|c|c|c|c|}
\hline Comp. & $\mathrm{R} 1$ & R2 & R3 & $\mathrm{WT} \mathrm{pEC}_{50}$ & $\mathrm{Y}_{188 \mathrm{~L} \mathrm{pEC}} \mathrm{p}_{50}$ \\
\hline 56 & & & $-\mathrm{CH}_{3}$ & 9.22 & 7.16 \\
\hline 57 & & & $-\mathrm{CH}_{3}$ & 9.30 & 6.82 \\
\hline 58 & & & $-\mathrm{CH}_{3}$ & 9.00 & 6.32 \\
\hline 59 & & & $-\mathrm{CH}_{3}$ & 9.52 & 6.48 \\
\hline 60 & & & $-\mathrm{CH}_{3}$ & 9.52 & 7.92 \\
\hline 61 & & & $-\mathrm{CH}_{3}$ & 9.30 & 7.01 \\
\hline 62 & & & $-\mathrm{CH}_{3}$ & 9.30 & 7.24 \\
\hline 63 & & & $-\mathrm{CH}_{3}$ & 9.15 & 6.34 \\
\hline 64 & & & $-\mathrm{CH}_{3}$ & 9.10 & 6.70 \\
\hline 65 & & & $-\mathrm{CH}_{3}$ & 9.10 & 6.80 \\
\hline 66 & & & $-\mathrm{CH}_{3}$ & 8.52 & 6.70 \\
\hline
\end{tabular}


Table 2 continued<smiles>[R7]NC(=O)CSc1nnc([R3])n1[R2]</smiles>

\begin{tabular}{|c|c|c|c|c|c|}
\hline Comp. & $\mathrm{R} 1$ & $\mathrm{R} 2$ & $\mathrm{R} 3$ & $\mathrm{WT}_{\mathrm{pEC}} \mathrm{C}_{50}$ & $\mathrm{Y}_{188 \mathrm{~L} \mathrm{pEC}} \mathrm{p}$ \\
\hline 67 & & & $-\mathrm{CH}_{3}$ & 9.00 & 6.96 \\
\hline 68 & & & $-\mathrm{CH}_{3}$ & 9.40 & 6.62 \\
\hline 69 & & & $-\mathrm{CH}_{3}$ & 9.40 & - \\
\hline 70 & & & $-\mathrm{H}$ & 7.15 & - \\
\hline 71 & & & $-\mathrm{CH}_{3}$ & 7.00 & - \\
\hline 72 & & & $\mathrm{CH}_{3}$ & 10.00 & - \\
\hline 73 & & & $-\mathrm{CF}_{3}$ & 9.30 & - \\
\hline 74 & & & $-\mathrm{CH}_{3}$ & 9.40 & - \\
\hline 75 & & & $-\mathrm{CH}_{3}$ & 9.30 & 6.72 \\
\hline 76 & & & $-\mathrm{CF}_{3}$ & 9.30 & 7.31 \\
\hline 77 & & & $-\mathrm{CH}_{3}$ & 8.40 & 5.62 \\
\hline 78 & & & $-\mathrm{CF}_{3}$ & 8.70 & 6.74 \\
\hline
\end{tabular}


Table 2 continued

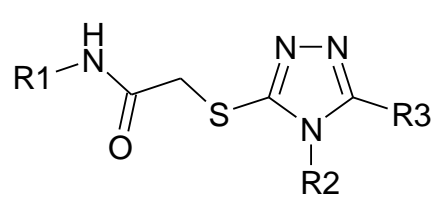

\begin{tabular}{|c|c|c|c|c|c|}
\hline Comp. & $\mathrm{R} 1$ & $\mathrm{R} 2$ & R3 & $\mathrm{WT}_{\mathrm{pEC}} \mathrm{C}_{50}$ & $\mathrm{Y}_{188 \mathrm{~L}} \mathrm{pEC}_{50}$ \\
\hline 79 & & & $-\mathrm{CH}_{3}$ & 9.70 & 7.70 \\
\hline 80 & & & $-\mathrm{CF}_{3}$ & 9.40 & 7.60 \\
\hline 81 & & & $-\mathrm{CH}_{3}$ & 9.00 & 6.41 \\
\hline 82 & & & $-\mathrm{CH}_{3}$ & 9.22 & 8.22 \\
\hline 83 & & & $-\mathrm{CH}_{3}$ & 10.00 & 8.40 \\
\hline 84 & & & $-\mathrm{CF}_{3}$ & 8.52 & 7.59 \\
\hline 85 & & & $-\mathrm{CH}_{3}$ & 9.22 & 7.82 \\
\hline 86 & & & $-\mathrm{CH}_{3}$ & 9.15 & 6.96 \\
\hline 87 & & & $-\mathrm{CF}_{3}$ & 9.40 & 7.85 \\
\hline 88 & & & $-\mathrm{CH}_{3}$ & 9.10 & 6.43 \\
\hline
\end{tabular}


Table 2 continued<smiles>[R7]NC(=O)CSc1nnc([R3])n1[R2]</smiles>

\begin{tabular}{|c|c|c|c|c|c|}
\hline Comp. & $\mathrm{R} 1$ & $\mathrm{R} 2$ & R3 & $\mathrm{WT}_{\mathrm{pEC}} \mathrm{p}_{50}$ & $\mathrm{Y}_{188 \mathrm{~L}} \mathrm{pEC}_{50}$ \\
\hline 89 & & & $-\mathrm{CH}_{3}$ & 9.00 & 7.17 \\
\hline 90 & & & $-\mathrm{CF}_{3}$ & 8.40 & 7.39 \\
\hline 91 & & & $-\mathrm{CH}_{3}$ & 9.15 & 7.96 \\
\hline 92 & & & $-\mathrm{CF}_{3}$ & 9.00 & 8.40 \\
\hline 93 & & & $-\mathrm{CH}_{3}$ & 9.30 & 7.06 \\
\hline 94 & & & $-\mathrm{CF}_{3}$ & 8.70 & 8.15 \\
\hline 95 & & & $-\mathrm{CH}_{3}$ & 8.70 & 7.00 \\
\hline 96 & & & $-\mathrm{CH}_{3}$ & 9.10 & 6.72 \\
\hline 97 & & & $-\mathrm{CH}_{3}$ & 9.30 & - \\
\hline
\end{tabular}




\section{Figure captions}

Fig. 1 Chemical structure of TTs 1-31 (series 1) and 32-97 (series 2)

Fig. 2 Docking analysis into HIV-1 reverse transcriptase X-ray structure (2RKI): Compound $18 \mathrm{x}$-ray pose is reported in line, colored in dark pink. Docking pose of 18 (colored in green) and docking pose of 79 (color code: C. white; N. blue; O. red; S. yellow) are reported in stick. RT P1 and P2 pockets, and the most important residues are labelled. Hydrogen bonds are colored in yellow

Fig. 3 Contour maps of model A CoMFA steric regions (a) (green, favored; yellow, disfavored) and CoMFA electrostatic areas (b) are displayed around compounds $\mathbf{1 5}$ (as representative of series 1 TTs, C: pink) and $\mathbf{8 3}$ (as representative of series 2 TTs, C: white). Blue regions are favorable for more positively charged groups; red regions are favorable for less positively charged groups. Ligands are depicted in stick mode and colored by atom type

Fig. 4 Contour maps of model A CoMSIA hydrophobic regions (yellow, favored; white, disfavored) are depicted around compounds 15 (as representative of series 1 TTs, C: pink) and $\mathbf{8 3}$ (as representative of series 2 TTs, C: white), shown in stick mode and colored by atom type

Fig. 5 Distribution of experimental and predicted $\mathrm{pEC}_{50}$ values for training set compounds according to model B CoMFA analysis (a), for test set compounds according to model B CoMFA analysis (b), for training set compounds according to model B CoMSIA analysis (c), and for test set compounds according to model B CoMSIA analysis (d)

Fig. 6 Contour maps of model B CoMFA steric regions (a) (green, favored; yellow, disfavored) and CoMFA electrostatic areas (b) are displayed around compound 92 (in stick, colored by atom type). Blue regions are favorable for more positively charged groups; red regions are favorable for less positively charged groups 
Fig. 7 Contour maps of model B CoMSIA hydrophobic regions (yellow, favored; white, disfavored) are depicted around compounds 92, shown in stick mode and colored by atom type 


\section{Captions to Online Resources:}

\section{Online Resource 1}

Summary of Model A CoMFA results; Summary of Model A CoMSIA results

\section{Online Resource 2}

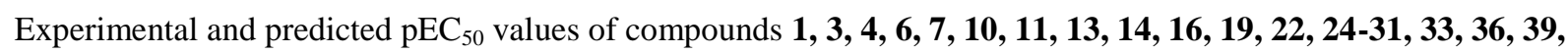
41, 45, 48-51, 53, 54, 57-60, 64-71, 77, 78, 80, 81, 84, 86-88, 90, 91, 94-96 (model A training set); Experimental and predicted $\mathrm{pEC}_{50}$ values of compounds $2,5, \mathbf{8}, \mathbf{9}, \mathbf{1 2}, \mathbf{1 5}, \mathbf{1 7}, \mathbf{1 8}, \mathbf{2 0}, \mathbf{2 1}, \mathbf{2 3}, 32,34,35,37,38,40,42-44,46$, 47, 52, 55, 56, 61-63, 72-76, 79, 82, 83, 85, 89, 92, 93, 97 (model A test set).

\section{Online Resource 3}

Model A CoMSIA hydrogen bond acceptor polihedra (a) and hydrogen bond donor polihedra (b) are shown around compounds $\mathbf{1 5}$ (as representative of series 1 TTs, C: pink) and $\mathbf{8 3}$ (as representative of series 2 TTs, C: white), depicted in stick mode and colored by atom type. H-bond acceptor groups: magenta, favored; green, disfavored. H-bond donor groups: cyan favored; purple, disfavored

Model B CoMSIA hydrogen bond acceptor polihedra (a) and hydrogen bond donor polihedra (b) are shown around compounds $\mathbf{9 2}$, depicted in stick mode and colored ed by atom type. H-bond acceptor groups: magenta, favored; green, disfavored. H-bond donor groups: cyan, favored; purple, disfavored

\section{Online Resource 4}

Summary of Model B CoMFA results; Summary of Model B CoMSIA results

\section{Online Resource 5}

Experimental and predicted $\mathrm{pEC}_{50}$ values of compounds 39-44, 47, 53-59, 61-64, 67, 68, 75-80, 82-92, 95 (model B training set); experimental and predicted $\mathrm{pEC}_{50}$ values of compounds $45,46,60,65,66,81,93,94,96$ (model B test set) 
3,4,5-Trisubstituted-1,2,4-4H-triazoles as WT and Y188L mutant HIV-1 non-nucleoside reverse transcriptase inhibitors: Docking-based CoMFA and CoMSIA analyses

Journal of Molecular Modeling

Elena Cichero*, Laura Buffa and Paola Fossa

Dipartimento di Scienze Farmaceutiche. Università degli Studi di Genova. Viale Benedetto XV n.3. 16132 - Genova. Italy

*Corresponding author: phone: +39-010-3538361; fax: +39-010-3538358; email:cichero@unige.it 
Summary of Model A CoMFA results

\begin{tabular}{|l|c|}
\hline No. compounds & 56 \\
\hline Optimal number of components (ONC) & 5 \\
\hline Leave one out $\mathrm{r}^{2}\left(\mathrm{r}_{\text {loo }}^{2}\right)$ & 0.855 \\
\hline Cross-validated ${ }^{2}\left(\mathrm{r}^{2}{ }_{\mathrm{vv}}\right)$ & 0.859 \\
\hline Std. error of estimate (SEE) & 0.229 \\
\hline Non cross-validated ${ }^{2}\left(\mathrm{r}^{2}{ }_{\mathrm{ncv}}\right)$ & 0.984 \\
\hline F value & 600.792 \\
\hline Steric contribution & 0.700 \\
\hline Electrostatic contribution & 0.300 \\
\hline Bootstrap $\mathrm{r}^{2}\left(\mathrm{r}_{\text {boot }}^{2}\right)$ & 0.990 \\
\hline Standard error of estimate $\mathrm{r}_{\text {boot }}^{2}\left(\mathrm{SEE} \mathrm{r}_{\text {boot }}^{2}\right)$ & 0.181 \\
\hline Test set $\mathrm{r}^{2}\left(\mathrm{r}_{\text {pred }}^{2}\right)$ & 0.80 \\
\hline
\end{tabular}


Summary of Model A CoMSIA results

\begin{tabular}{|c|c|}
\hline No. compounds & 56 \\
\hline Optimal number of components (ONC) & 5 \\
\hline Leave one out $r^{2}\left(r^{2}{ }_{\text {loo }}\right)$ & 0.886 \\
\hline Cross-validated $\mathrm{r}^{2}\left(\mathrm{r}_{\mathrm{cv}}^{2}\right)$ & 0.892 \\
\hline Std. error of estimate (SEE) & 0.314 \\
\hline Non cross-validated $r^{2}\left(r_{n c v}^{2}\right)$ & 0.970 \\
\hline F value & 314.920 \\
\hline Steric contribution & 0.178 \\
\hline Electrostatic contribution & 0.144 \\
\hline Hydrophobic contribution & 0.257 \\
\hline H-bond acceptor contribution & 0.230 \\
\hline H-bond donor contribution & 0.191 \\
\hline Bootstrap $r^{2}\left(r^{2}{ }_{\text {boot}}\right)$ & 0.974 \\
\hline Standard error of estimate $r_{\text {boot }}^{2}\left(\operatorname{SEE} r_{\text {boot }}^{2}\right)$ & 0.298 \\
\hline Test set $r^{2}\left(r_{\text {pred }}^{2}\right)$ & 0.82 \\
\hline
\end{tabular}


3,4,5-Trisubstituted-1,2,4-4H-triazoles as WT and Y188L mutant HIV-1 non-nucleoside reverse transcriptase inhibitors: Docking-based CoMFA and CoMSIA analyses

Journal of Molecular Modeling

Elena Cichero*, Laura Buffa and Paola Fossa

Dipartimento di Scienze Farmaceutiche. Università degli Studi di Genova. Viale Benedetto XV n.3. 16132 - Genova. Italy

*Corresponding author: phone: +39-010-3538361; fax: +39-010-3538358; email:cichero@unige.it 
Experimental and predicted $\mathrm{pEC}_{50}$ values of compounds 1, 3, 4, 6, 7, 10, 11, 13, 14, 16, 19, 22, 24-31, 33, 36, 39, 41, 45, 48-51, 53, 54, 57-60, 64-71, 77, 78, 80, 81, 84, 86-88, 90, 91, 94-96 (model A training set)

\begin{tabular}{|c|c|c|c|c|c|}
\hline \multirow[b]{2}{*}{ Compound } & \multirow[b]{2}{*}{ Exp.pEC ${ }_{50}$} & \multicolumn{2}{|c|}{ CoMFA Model } & \multicolumn{2}{|c|}{ CoMSIA Model } \\
\hline & & Pred. $\mathrm{pEC}_{50}$ & Residual & Pred. $\mathrm{pEC}_{50}$ & Residual \\
\hline 1 & 4.63 & 5.34 & -0.71 & 4.94 & -0.31 \\
\hline 3 & 4.98 & 5.11 & -0.13 & 4.88 & 0.10 \\
\hline 4 & 5.43 & 5.17 & 0.26 & 5.08 & 0.36 \\
\hline 6 & 4.38 & 4.48 & -0.10 & 4.52 & -0.14 \\
\hline 7 & 4.64 & 4.76 & -0.12 & 4.54 & 0.10 \\
\hline 10 & 5.08 & 5.17 & -0.09 & 4.81 & 0.27 \\
\hline 11 & 4.55 & 4.63 & -0.08 & 4.88 & -0.33 \\
\hline 13 & 5.24 & 5.20 & 0.04 & 5.07 & 0.18 \\
\hline 14 & 5.52 & 5.46 & 0.06 & 5.17 & 0.35 \\
\hline 16 & 5.80 & 5.51 & 0.29 & 5.66 & 0.14 \\
\hline 19 & 5.77 & 5.53 & 0.24 & 5.69 & 0.08 \\
\hline 22 & 5.77 & 6.04 & -0.27 & 5.92 & -0.15 \\
\hline 24 & 5.05 & 5.36 & -0.31 & 5.57 & -0.52 \\
\hline 25 & 5.48 & 5.53 & -0.05 & 5.76 & -0.28 \\
\hline 26 & 5.89 & 5.67 & 0.22 & 5.82 & 0.07 \\
\hline 27 & 5.62 & 5.95 & -0.33 & 6.03 & -0.41 \\
\hline 28 & 5.46 & 5.37 & 0.09 & 5.54 & -0.08 \\
\hline 29 & 6.00 & 5.63 & 0.37 & 5.71 & 0.29 \\
\hline 30 & 5.96 & 5.75 & 0.21 & 5.89 & 0.07 \\
\hline 31 & 6.14 & 5.89 & 0.25 & 5.96 & 0.18 \\
\hline 33 & 6.40 & 6.57 & -0.17 & 6.94 & -0.54 \\
\hline 36 & 6.96 & 6.93 & 0.04 & 7.33 & -0.37 \\
\hline 39 & 8.40 & 8.56 & -0.16 & 8.45 & -0.04 \\
\hline 41 & 9.00 & 8.86 & 0.15 & 8.62 & 0.38 \\
\hline 45 & 9.00 & 9.08 & -0.08 & 8.78 & 0.22 \\
\hline 48 & 8.52 & 8.51 & 0.01 & 8.18 & 0.34 \\
\hline 49 & 8.15 & 8.07 & 0.08 & 8.20 & -0.04 \\
\hline
\end{tabular}


continued

\begin{tabular}{|c|c|c|c|c|c|}
\hline \multirow[b]{2}{*}{ Compound } & \multirow[b]{2}{*}{ Exp. pEC $\mathrm{C}_{50}$} & \multicolumn{2}{|c|}{ CoMFA Model } & \multicolumn{2}{|c|}{ CoMSIA Model } \\
\hline & & Pred. $\mathrm{pEC}_{50}$ & Residual & Pred. $\mathrm{pEC}_{50}$ & Residual \\
\hline 50 & 7.00 & 7.50 & -0.50 & 7.86 & -0.86 \\
\hline 51 & 8.30 & 8.00 & 0.30 & 7.84 & 0.46 \\
\hline 53 & 8.70 & 8.71 & -0.01 & 8.60 & 0.10 \\
\hline 54 & 8.15 & 7.86 & 0.29 & 7.82 & 0.34 \\
\hline 57 & 9.30 & 7.26 & 2.04 & 7.29 & 2.01 \\
\hline 58 & 9.00 & 9.24 & -0.24 & 9.14 & -0.14 \\
\hline 59 & 9.52 & 9.46 & 0.06 & 9.19 & 0.33 \\
\hline 60 & 9.52 & 9.60 & -0.08 & 9.23 & 0.29 \\
\hline 64 & 9.10 & 8.82 & 0.28 & 8.73 & 0.37 \\
\hline 65 & 9.10 & 8.95 & 0.15 & 9.30 & -0.20 \\
\hline 66 & 8.52 & 8.57 & -0.05 & 8.97 & -0.45 \\
\hline 67 & 9.00 & 8.98 & 0.02 & 9.39 & -0.39 \\
\hline 68 & 9.40 & 9.41 & -0.01 & 9.26 & 0.14 \\
\hline 69 & 9.40 & 9.40 & 0.00 & 9.28 & 0.12 \\
\hline 70 & 7.15 & 6.73 & 0.42 & 6.89 & 0.26 \\
\hline 71 & 7.00 & 6.88 & 0.12 & 7.01 & -0.01 \\
\hline 77 & 8.40 & 8.51 & -0.11 & 8.41 & -0.01 \\
\hline 78 & 8.70 & 8.71 & -0.01 & 8.81 & -0.11 \\
\hline 80 & 9.40 & 9.33 & 0.08 & 9.38 & 0.02 \\
\hline 81 & 9.00 & 8.93 & 0.07 & 8.60 & 0.40 \\
\hline 84 & 8.52 & 8.53 & -0.01 & 8.77 & -0.25 \\
\hline 86 & 9.15 & 9.23 & -0.08 & 9.28 & -0.13 \\
\hline 87 & 9.40 & 9.15 & 0.25 & 9.18 & 0.22 \\
\hline 88 & 9.10 & 9.31 & -0.21 & 8.99 & 0.11 \\
\hline 90 & 8.40 & 8.45 & -0.05 & 8.33 & 0.07 \\
\hline 91 & 9.15 & 8.95 & 0.20 & 9.02 & 0.13 \\
\hline 94 & 8.70 & 9.10 & -0.40 & 9.43 & -0.73 \\
\hline 95 & 8.70 & 8.79 & -0.09 & 8.66 & 0.04 \\
\hline 96 & 9.10 & 9.19 & -0.09 & 9.16 & -0.06 \\
\hline
\end{tabular}




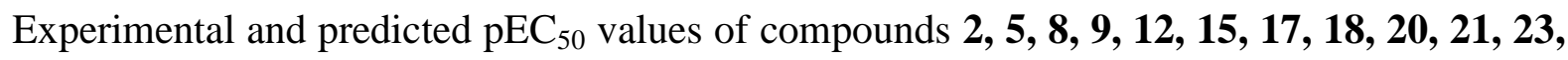
$32,34,35,37,38,40,42-44,46,47,52,55,56,61-63,72-76,79,82,83,85,89,92,93,97$ (model A test set).

\begin{tabular}{|c|c|c|c|c|c|}
\hline \multirow[b]{2}{*}{ Compound } & \multirow[b]{2}{*}{ Exp. $\mathrm{pEC}_{50}$} & \multicolumn{2}{|c|}{ CoMFA Model } & \multicolumn{2}{|c|}{ CoMSIA Model } \\
\hline & & Pred. $\mathrm{pEC}_{50}$ & Residual & Pred. $\mathrm{pEC}_{50}$ & Residual \\
\hline 2 & 5.34 & 4.83 & 0.51 & 5.03 & 0.31 \\
\hline 5 & 5.55 & 5.54 & 0.01 & 4.99 & 0.56 \\
\hline 8 & 5.32 & 4.76 & 0.56 & 4.64 & 0.69 \\
\hline 9 & 5.08 & 5.11 & -0.03 & 4.57 & 0.51 \\
\hline 12 & 4.63 & 5.73 & -1.10 & 5.80 & -1.17 \\
\hline 15 & 6.88 & 5.32 & 1.56 & 5.54 & 1.34 \\
\hline 17 & 4.29 & 4.97 & -0.68 & 5.20 & -0.91 \\
\hline 18 & 6.36 & 5.53 & 0.83 & 5.69 & 0.67 \\
\hline 20 & 5.70 & 5.35 & 0.35 & 5.31 & 0.39 \\
\hline 21 & 6.24 & 5.82 & 0.42 & 5.77 & 0.48 \\
\hline 23 & 5.33 & 5.73 & -0.40 & 5.89 & -0.56 \\
\hline 32 & 7.22 & 7.16 & 0.06 & 7.08 & 0.15 \\
\hline 34 & 9.15 & 7.48 & 1.67 & 7.58 & 1.57 \\
\hline 35 & 9.22 & 8.18 & 1.04 & 8.41 & 0.82 \\
\hline 37 & 9.70 & 8.21 & 1.49 & 8.58 & 1.12 \\
\hline 38 & 10.00 & 8.36 & 1.65 & 8.73 & 1.27 \\
\hline 40 & 8.10 & 8.17 & -0.07 & 7.96 & 0.14 \\
\hline 42 & 9.00 & 8.32 & 0.68 & 8.35 & 0.65 \\
\hline 43 & 9.00 & 8.40 & 0.60 & 8.57 & 0.43 \\
\hline 44 & 9.00 & 8.40 & 0.61 & 8.20 & 0.80 \\
\hline 46 & 9.00 & 9.76 & -0.76 & 9.22 & -0.22 \\
\hline 47 & 9.00 & 8.59 & 0.41 & 8.55 & 0.45 \\
\hline 52 & 9.40 & 8.00 & 1.40 & 8.20 & 1.20 \\
\hline 55 & 9.00 & 8.89 & 0.11 & 8.92 & 0.08 \\
\hline 56 & 9.22 & 8.27 & 0.95 & 8.13 & 1.10 \\
\hline 61 & 9.30 & 9.48 & -0.18 & 9.02 & 0.28 \\
\hline 62 & 9.30 & 8.13 & 1.17 & 8.29 & 1.01 \\
\hline 63 & 9.15 & 9.54 & -0.39 & 9.20 & -0.05 \\
\hline 72 & 10.00 & 8.88 & 1.12 & 9.00 & 1.00 \\
\hline 73 & 9.30 & 8.77 & 0.53 & 7.98 & 1.32 \\
\hline 74 & 9.40 & 8.76 & 0.64 & 8.43 & 0.97 \\
\hline 75 & 9.30 & 8.57 & 0.73 & 8.43 & 0.87 \\
\hline
\end{tabular}




\begin{tabular}{|l|l|l|l|l|l|}
\hline $\mathbf{7 6}$ & 9.30 & 9.13 & 0.17 & 9.19 & 0.11 \\
\hline
\end{tabular}


continued

\begin{tabular}{|c|c|c|c|c|c|}
\hline \multirow{2}{*}{ Compound } & & \multicolumn{2}{|c|}{ CoMFA Model } & \multicolumn{2}{c|}{ CoMSIA Model } \\
\cline { 2 - 6 } & Exp. pEC $_{50}$ & Pred. $\mathrm{pEC}_{50}$ & Residual & Pred. $\mathrm{pEC}_{50}$ & Residual \\
\hline $\mathbf{7 9}$ & 9.70 & 8.62 & 1.08 & 8.32 & 1.38 \\
\hline $\mathbf{8 2}$ & 9.22 & 9.64 & -0.42 & 9.53 & -0.31 \\
\hline $\mathbf{8 3}$ & 10.00 & 8.95 & 1.05 & 9.08 & 0.92 \\
\hline $\mathbf{8 5}$ & 9.22 & 8.89 & 0.33 & 8.80 & 0.42 \\
\hline $\mathbf{8 9}$ & 9.00 & 8.80 & 0.20 & 8.87 & 0.13 \\
\hline $\mathbf{9 2}$ & 9.00 & 8.70 & 0.30 & 8.88 & 0.12 \\
\hline $\mathbf{9 3}$ & 9.30 & 9.26 & 0.04 & 9.47 & -0.17 \\
\hline $\mathbf{9 7}$ & 9.30 & 8.01 & 1.29 & 8.26 & 1.04 \\
\hline
\end{tabular}


3,4,5-Trisubstituted-1,2,4-4H-triazoles as WT and Y188L mutant HIV-1 non-nucleoside reverse transcriptase inhibitors: Docking-based CoMFA and CoMSIA analyses

Journal of Molecular Modeling

Elena Cichero*, Laura Buffa and Paola Fossa

Dipartimento di Scienze Farmaceutiche. Università degli Studi di Genova. Viale Benedetto XV n.3. 16132 - Genova. Italy

*Corresponding author: phone: +39-010-3538361; fax: +39-010-3538358; email:cichero@unige.it 

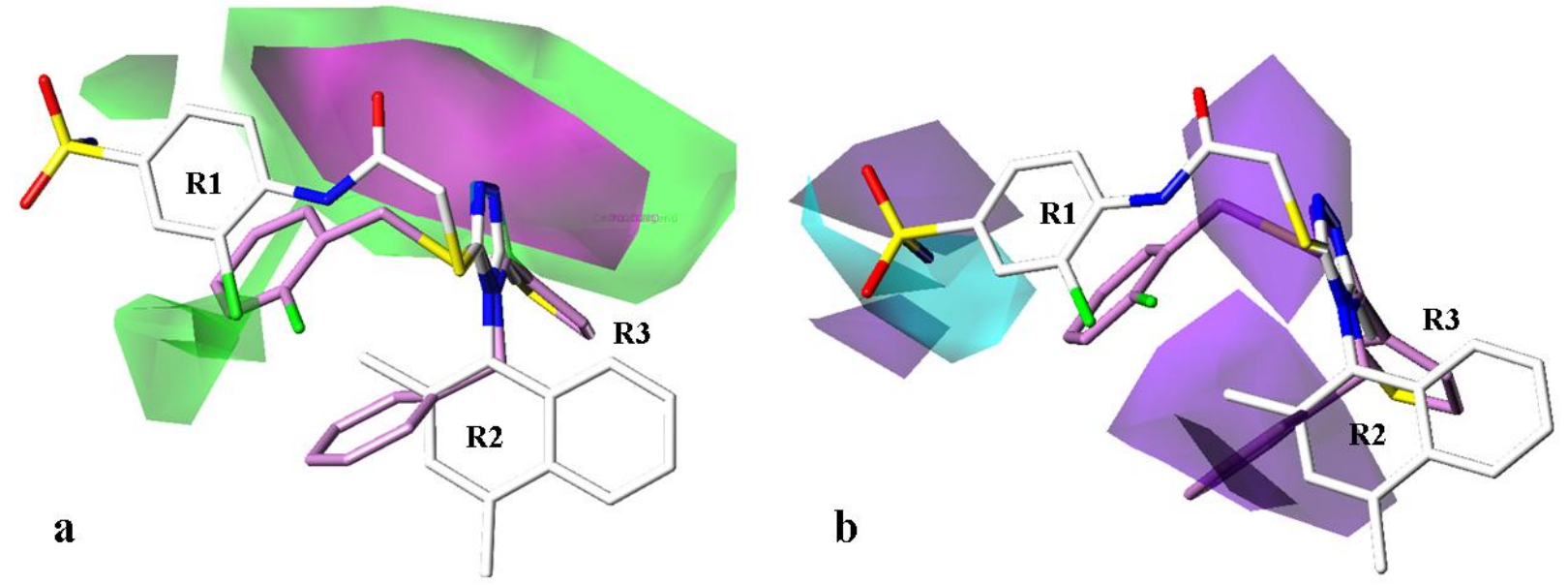

Model A CoMSIA hydrogen bond acceptor polihedra (a) and hydrogen bond donor polihedra (b) are shown around compounds 15 (as representative of series 1 TTs, C: pink) and 83 (as representative of series 2 TTs, C: white), depicted in stick mode and coloured by atom type. H-bond acceptor groups: magenta, favoured; green, disfavoured. H-bond donor groups: cyan favoured; purple, disfavoured 

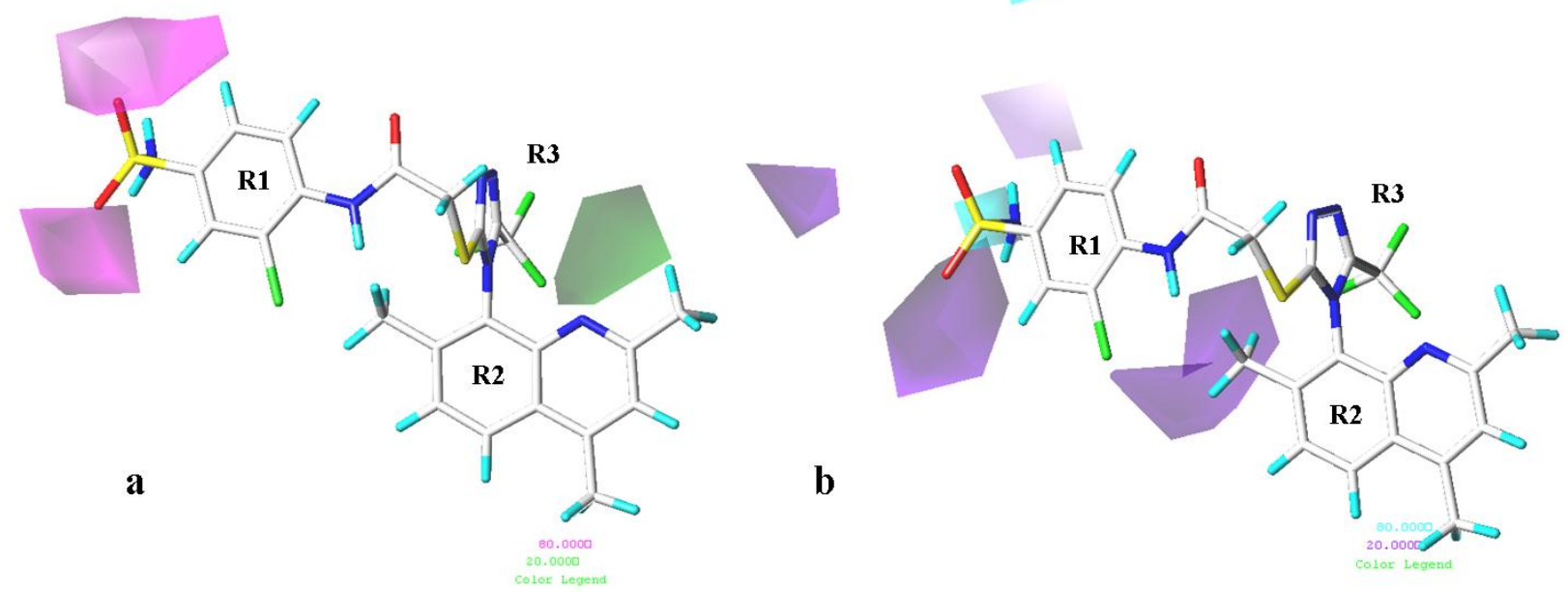

Model B CoMSIA hydrogen bond acceptor polihedra (a) and hydrogen bond donor polihedra (b) are shown around compounds 92, depicted in stick mode and coloured by atom type. H-bond acceptor groups: magenta, favoured; green, disfavoured. H-bond donor groups: cyan, favoured; purple, disfavoured 
3,4,5-Trisubstituted-1,2,4-4H-triazoles as WT and Y188L mutant HIV-1 non-nucleoside reverse transcriptase inhibitors: Docking-based CoMFA and CoMSIA analyses

Journal of Molecular Modeling

Elena Cichero*, Laura Buffa and Paola Fossa

Dipartimento di Scienze Farmaceutiche. Università degli Studi di Genova. Viale Benedetto XV n.3. 16132 - Genova. Italy

*Corresponding author: phone: +39-010-3538361; fax: +39-010-3538358; email:cichero@unige.it 
Summary of Model B CoMFA results

\begin{tabular}{|c|c|}
\hline No. compounds & 38 \\
\hline Optimal number of components (ONC) & 6 \\
\hline Leave one out $\mathrm{r}^{2}\left(\mathrm{r}_{\text {loo }}^{2}\right)$ & 0.757 \\
\hline Cross-validated $r^{2}\left(r_{c v}^{2}\right)$ & 0.782 \\
\hline Std. error of estimate (SEE) & 0.149 \\
\hline Non cross-validated $r^{2}\left(r_{n c v}^{2}\right)$ & 0.967 \\
\hline F value & 149.927 \\
\hline Steric contribution & 0.684 \\
\hline Electrostatic contribution & 0.316 \\
\hline Bootstrap $r^{2}\left(r^{2}{ }_{\text {boot }}\right)$ & 0.983 \\
\hline Standard error of estimate $r_{\text {boot }}^{2}\left(\right.$ SEE $\left.r_{\text {boot }}^{2}\right)$ & 0.102 \\
\hline Test set $r^{2}\left(r_{\text {pred }}^{2}\right)$ & 0.64 \\
\hline
\end{tabular}


Summary of Model B CoMSIA results

\begin{tabular}{|l|c|}
\hline No. compounds & 38 \\
\hline Optimal number of components $(\mathrm{ONC})$ & 5 \\
\hline Leave one out $\mathrm{r}^{2}\left(\mathrm{r}^{2}{ }_{\text {loo }}\right)$ & 0.671 \\
\hline Cross-validated $\mathrm{r}^{2}\left(\mathrm{r}_{\mathrm{cv}}{ }\right)$ & 0.610 \\
\hline Std. error of estimate $(\mathrm{SEE})$ & 0.236 \\
\hline Non cross-validated $\mathrm{r}^{2}\left(\mathrm{r}^{2}{ }_{\mathrm{ncv}}\right)$ & 0.913 \\
\hline F value & 67.277 \\
\hline Steric contribution & 0.172 \\
\hline Electrostatic contribution & 0.153 \\
\hline Hydrophobic contribution & 0.231 \\
\hline H-bond acceptor contribution & 0.164 \\
\hline H-bond donor contribution & 0.281 \\
\hline Bootstrap $\mathrm{r}^{2}\left(\mathrm{r}^{2}{ }_{\text {boot }}\right)$ & 0.941 \\
\hline Standard error of estimate ${ }^{2}{ }_{\text {boot }}\left(\mathrm{SEE}^{2}{ }_{\text {boot }}\right)$ & 0.188 \\
\hline Test set $\mathrm{r}^{2}\left(\mathrm{r}^{2}{ }_{\text {pred }}\right)$ & 0.73 \\
\hline
\end{tabular}


3,4,5-Trisubstituted-1,2,4-4H-triazoles as WT and Y188L mutant HIV-1 non-nucleoside reverse transcriptase inhibitors: Docking-based CoMFA and CoMSIA analyses

Journal of Molecular Modeling

Elena Cichero*, Laura Buffa and Paola Fossa

Dipartimento di Scienze Farmaceutiche. Università degli Studi di Genova. Viale Benedetto XV n.3. 16132 - Genova. Italy

*Corresponding author: phone: +39-010-3538361; fax: +39-010-3538358; email:cichero@unige.it 
Experimental and predicted $\mathrm{pEC}_{50}$ values of compounds 39-44, 47, 53-59, 61-64, 67, 68, 7580, 82-92, 95 (model B training set)

\begin{tabular}{|c|c|c|c|c|c|}
\hline \multirow[b]{2}{*}{ Compound } & \multirow[b]{2}{*}{ Exp.pEC ${ }_{50}$} & \multicolumn{2}{|c|}{ CoMFA Model } & \multicolumn{2}{|c|}{ CoMSIA Model } \\
\hline & & Pred. $\mathrm{pEC}_{50}$ & Residual & Pred. $\mathrm{pEC}_{50}$ & Residual \\
\hline 39 & 6.23 & 6.17 & 0.06 & 6.23 & 0.00 \\
\hline 40 & 5.24 & 5.21 & 0.03 & 5.44 & -0.20 \\
\hline 41 & 6.70 & 6.58 & 0.12 & 6.62 & 0.08 \\
\hline 42 & 7.00 & 6.97 & 0.03 & 6.75 & 0.25 \\
\hline 43 & 6.80 & 7.01 & -0.21 & 6.84 & -0.04 \\
\hline 44 & 6.96 & 6.99 & -0.03 & 7.11 & -0.15 \\
\hline 47 & 6.49 & 6.52 & -0.03 & 6.47 & 0.02 \\
\hline 53 & 6.14 & 6.21 & -0.07 & 6.30 & -0.16 \\
\hline 54 & 5.38 & 5.43 & -0.04 & 5.67 & -0.29 \\
\hline 55 & 6.68 & 6.60 & 0.08 & 6.41 & 0.27 \\
\hline 56 & 7.16 & 7.04 & 0.12 & 6.98 & 0.18 \\
\hline 57 & 6.82 & 6.83 & -0.01 & 6.87 & -0.05 \\
\hline 58 & 6.32 & 6.69 & -0.37 & 6.59 & -0.27 \\
\hline 59 & 6.48 & 6.48 & 0.00 & 6.69 & -0.21 \\
\hline 61 & 7.01 & 7.03 & -0.02 & 6.98 & 0.03 \\
\hline 62 & 7.24 & 7.12 & 0.12 & 6.99 & 0.26 \\
\hline 63 & 6.34 & 6.22 & 0.13 & 6.13 & 0.21 \\
\hline 64 & 6.70 & 6.64 & 0.07 & 6.52 & 0.18 \\
\hline 67 & 6.96 & 7.08 & -0.12 & 6.97 & -0.01 \\
\hline 68 & 6.62 & 6.71 & -0.09 & 6.63 & -0.01 \\
\hline 75 & 6.72 & 6.76 & -0.04 & 6.86 & -0.14 \\
\hline 76 & 7.31 & 7.24 & 0.07 & 7.11 & 0.20 \\
\hline 77 & 5.62 & 5.59 & 0.03 & 5.49 & 0.13 \\
\hline 78 & 6.74 & 6.73 & 0.01 & 6.94 & -0.20 \\
\hline 79 & 7.70 & 7.51 & 0.19 & 7.73 & -0.03 \\
\hline 80 & 7.60 & 7.88 & -0.28 & 7.54 & 0.06 \\
\hline 82 & 8.22 & 8.03 & 0.19 & 7.93 & 0.30 \\
\hline 83 & 8.40 & 8.36 & 0.04 & 8.45 & -0.05 \\
\hline 84 & 7.59 & 7.84 & -0.25 & 8.16 & -0.57 \\
\hline 85 & 7.82 & 7.86 & -0.04 & 7.67 & 0.15 \\
\hline 86 & 6.96 & 7.17 & -0.21 & 7.47 & -0.51 \\
\hline 87 & 7.85 & 7.60 & 0.25 & 7.46 & 0.39 \\
\hline 88 & 6.43 & 6.24 & 0.19 & 6.26 & 0.17 \\
\hline
\end{tabular}




\begin{tabular}{|l|l|l|l|l|l|}
\hline $\mathbf{8 9}$ & 7.17 & 7.17 & 0.00 & 7.22 & -0.04 \\
\hline
\end{tabular}


Table 9. continued

\begin{tabular}{|c|c|c|c|c|c|}
\hline \multirow{2}{*}{ Compound } & & \multicolumn{2}{|c|}{ CoMFA Model } & \multicolumn{2}{c|}{ CoMSIA Model } \\
\cline { 2 - 6 } & Exp. pEC 50 & Pred. $\mathrm{pEC}_{50}$ & Residual & Pred. $\mathrm{pEC}_{50}$ & Residual \\
\hline $\mathbf{9 0}$ & 7.39 & 7.37 & 0.02 & 7.42 & -0.03 \\
\hline $\mathbf{9 1}$ & 7.96 & 7.94 & 0.02 & 8.01 & -0.05 \\
\hline $\mathbf{9 2}$ & 8.40 & 8.25 & 0.15 & 8.05 & 0.35 \\
\hline $\mathbf{9 5}$ & 7.00 & 7.09 & -0.09 & 7.23 & -0.23 \\
\hline
\end{tabular}


Experimental and predicted $\mathrm{pEC}_{50}$ values of compounds $45,46,60,65,66,81,93,94,96$ (model B test set)

\begin{tabular}{|c|c|c|c|c|c|}
\hline \multirow{2}{*}{ Compound } & & \multicolumn{2}{|c|}{ CoMFA Model } & \multicolumn{2}{c|}{ CoMSIA Model } \\
\cline { 2 - 6 } & Exp. pEC $_{50}$ & Pred. $\mathrm{pEC}_{50}$ & Residual & Pred. pEC 50 & Residual \\
\hline $\mathbf{4 5}$ & 7.05 & 7.21 & -0.16 & 7.04 & 0.01 \\
\hline $\mathbf{4 6}$ & 6.62 & 6.27 & 0.35 & 6.50 & 0.12 \\
\hline $\mathbf{6 0}$ & 7.92 & 7.53 & 0.39 & 7.84 & 0.08 \\
\hline $\mathbf{6 5}$ & 6.80 & 7.18 & -0.38 & 7.06 & -0.26 \\
\hline $\mathbf{6 6}$ & 6.70 & 6.62 & 0.08 & 6.90 & -0.20 \\
\hline $\mathbf{8 1}$ & 6.41 & 7.02 & -0.61 & 7.08 & -0.67 \\
\hline $\mathbf{9 3}$ & 7.06 & 7.33 & -0.27 & 7.31 & -0.25 \\
\hline $\mathbf{9 4}$ & 8.15 & 8.15 & 0.00 & 7.79 & 0.36 \\
\hline $\mathbf{9 6}$ & 6.72 & 6.31 & 0.41 & 6.53 & 0.19 \\
\hline
\end{tabular}

